\title{
SPATIAL CHANGE ANALISYS BASED ON NDVI VALUES USING LANDSAT DATA: CASE STUDY IN TETOVO, MACEDONIA
}

DOI: http://dx.doi.org/10.18509/GBP.2016.11

UDC: 528.837.04:629.783(497.751)

\author{
MSc. Gordana JOVANOVSKA ${ }^{1}$ \\ Ass. Prof. Dr. Ŭgur AVDAN ${ }^{1}$ \\ Ass. Prof. Dr. Nalan DEMIRCIOĞLU YILDIZ ${ }^{2}$ \\ ${ }^{1}$ Earth and Space Sciences Institute/Anadolu University Eskisehir - Turkey \\ ${ }^{2}$ Faculty of Architecture and Design/Ataturk University, Erzurum - Turkey
}

\begin{abstract}
The rapid urban growth of the cities is a result of the population growth and the negative effects on human health and quality life are obvious which makes the monitoring of the urban growth very important. In this study monitoring over the city Tetovo in the northwestern part of Republic of Macedonia was made using remote sensed satellite images from Landsat archive that is widely used for monitoring the Earth's surface. An attempt of mapping the urban area on an annual basis from the period of 1984 to 2015 was made. Change detection in rapidly growing areas was made using the NDVI (Normalized Difference Vegetation Index) values that were classified for distinguishing the differences between urban and vegetated areas. The study area covers nine cadaster municipalities with $14.6 \mathrm{~km}^{2}$. The results showed significant urban growth of $21.3 \%$ and $17.7 \%$ vegetation loss in the study area from 1984 to 2015.
\end{abstract}

Keywords: Remote Sensing, Urban growth, NDVI, Landsat, Time series, Change detection.

\section{INTRODUCTION}

Urbanization is increasing rapidly all around the globe. With the population growth, land cover is exposed to changes mostly with negative influence over the natural resources. Effective management and monitoring of land cover require spatial data at various scales in order to incorporate land use patterns, topography, hydrologic and vegetation parameters [1]. Land cover described the materials such as vegetation, rocks or water that are presented on the surface. Current information of land use and land cover is essential for many planning activities. Remote sensing methods are becoming increasingly important for mapping land use and land cover [2].

Landsat series of satellite provides the longest continuous record of satellite-based observation. The Landsat program has provided earth observation data since 1972. Landsat provides the only inventory of the global land surface over time on a seasonal basis, observing requirements for revealing both natural and human inducted landscape changes [3].

In this paper, using five Landsat 5 images and one Landsat 8 image, starting from 1984, until 2015, a 32-year land cover changes based on NDVI (Normalized Difference Vegetation Index) values has been made over nine populated cadaster municipalities (Dzepchishte, Poroj, Tetovo 1, Tetovo 2, Tetovo 3, Mala Rechica, Golema Rechica, Gorno Palchishte, Dolno Palchishte) in the city Tetovo in northwestern part of Republic 
of Macedonia. The NDVI values have been separated into four land cover types, water area, soil area, soil and vegetation mixture area and vegetation area. The main objective of this study was to investigate the city expansion and the loss of vegetation in Tetovo.

\section{STUDY AREA AND REMOTE SENSING DATA}

Tetovo is settled in the central part of Polog Valley, historically Tetovo had a great economic and strategic importance and therefore many rulers in the distant and recent past have tried to rule this bilateral strategic region. There are also the relevant links with neighboring regions in Derven ravine (Dervenska klisura) and the mountainous region of Grupchin that is located southeast through which the Polog region is connected with the Skopje region and beyond.

Southwest through the city of Gostivar and through the mountain gorges, Tetovo connects to Kichevo and Debar. Lastly through regional road Tetovo-Uroshevac as a plane, otherwise, only a small part, mainly the old city is situated in the foothills of Baltepe. The absolute altitude of the city between $450-500 \mathrm{~m}$. The first notes of Tetovo as a settlement dating from the classical period under the ancient name OANEUMIT.

Just beside the city, the European route E-65 is passing connecting Sweden and Greece with about 4,400 km length. The highway near Tetovo has been constructed between 1998 and 2002 (Figure 1).

Tetovo has grown over the years along with the population number. According to the Republic of Macedonia State Statistical Office, Tetovo is one of the three municipalities with biggest natural growth in 2014 [4]. Unfortunately at the end of 2015, Tetovo has been declared as the most polluted urban area globally, with 101.55 pollution index [5]. For the study area, six remote sensed Landsat 5 and Landsat 8 images were downloaded from the USGS web page (http://earthexplorer.usgs.gov/) and clipped according to the study area. The details of the Landsat images are presented in Table 1.

Table 1. Details of the used Landsat images.

\begin{tabular}{|c|c|c|c|}
\hline Landsat & Year & Month & Day \\
\hline 5 & 1984 & 7 & 1 \\
\hline 5 & 1990 & 7 & 2 \\
\hline 5 & 2003 & 7 & 22 \\
\hline 5 & 2009 & 7 & 22 \\
\hline 5 & 2011 & 7 & 12 \\
\hline 8 & 2015 & 7 & 7 \\
\hline
\end{tabular}




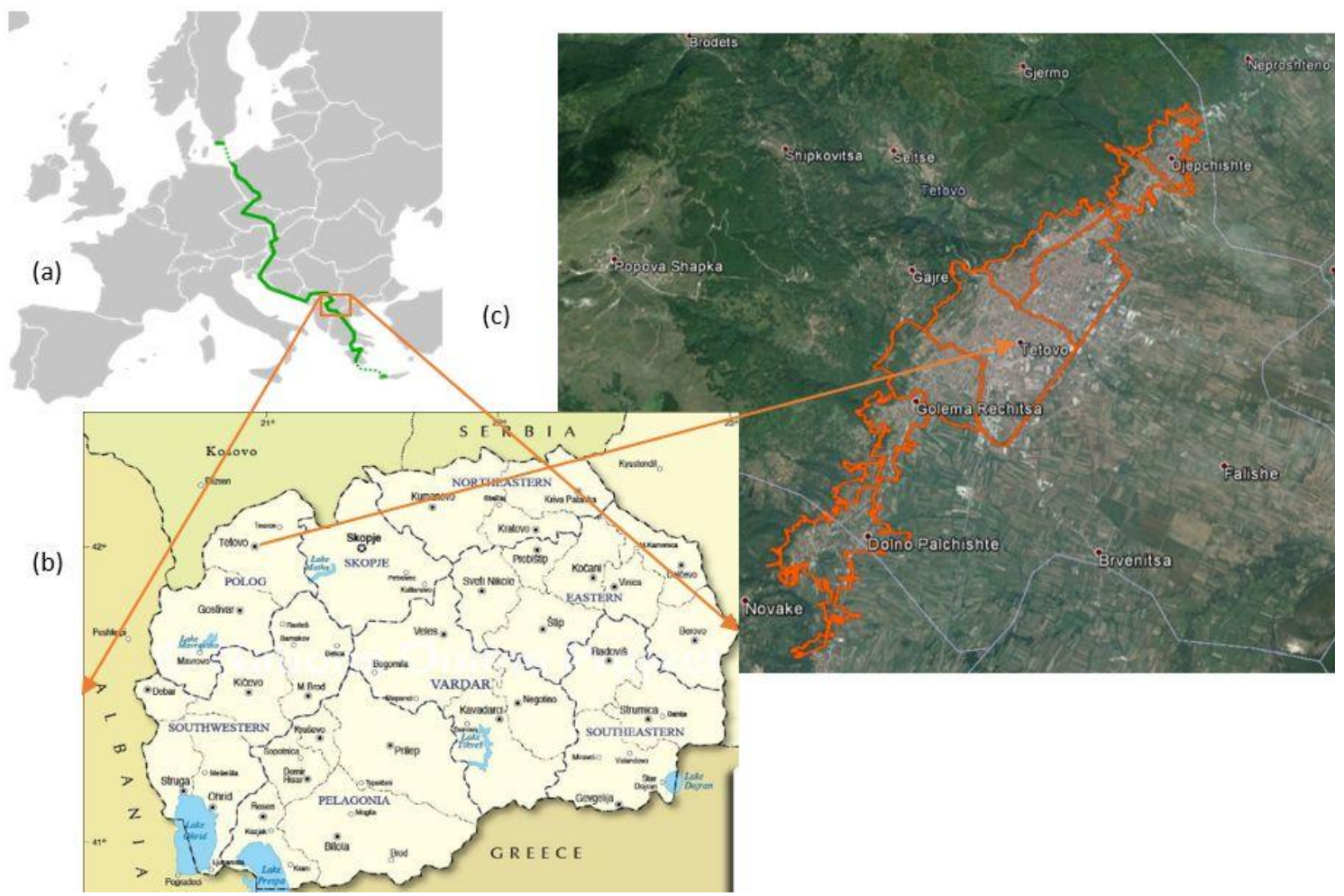

Figure 1. (a) - European route E65 - green line; (b) - Administrative Map of Republic of Macedonia (taken from http://www.nationsonline.org/); (c) - Satellite image from Tetovo and the surrounding and the study area highlighted with red line (taken from Google Earth).

It would have more appropriate if all the images were from the same satellite but since Landsat 5 mission have finished in 2013, Landsat 8 image was taken for 2015 year. For more accurate results, all of the satellite images were selected in July, when the green area is high and the images are cloudless.

\section{METHODS}

For the remote sensed images NDVI analyses were made. Landsat series of satellite images have been used to generate vegetation indices such as NDVI. NDVI not only maps the presence of vegetation on a pixel basis, but also provides measures of the amount or condition of vegetation within a pixel [6]. The NDVI is defined as

$$
N D V I=\frac{I R-R}{I R+R}
$$

where $\mathrm{R}$ is the red band and IR is the reflected Infra-Red wavelengths. Values for NDVI ranges 1.0 to -1.0. Higher values indicate higher concentration of green vegetation. Lower values indicate nonvegetated features, such as water, barren land, ice, snow or clouds [2].The NDVI values were classified into four land-cover types, for values smaller than 0 it was considered to be water area, values between 0 and 0.25 correspond to bared soil, from 0.25 to 0.50 mixture of soil and vegetation and values above 0.5 correspond to fully vegetated area. It was suggested that in global conditions the border between bared soil and mixture should be 0.2 [7] but after comparison with high resolution images, it was 
concluded that for this area the border should be changed to 0.25 . After the borders have been established classification and reclassification of the full study area, and every municipality separately was made. The analysis were made for the full study area as for every municipality separately.

\section{RESULTS \& DISCUTION}

The land cover classification results (Table 1) show that the biggest loss of vegetation was noticed in the period between 1984 and 1990. In 2009 there is increase in the vegetation area, but until 2015 the values are drastically falling to $4.4 \%$ vegetation area. The differences in the soil area are biggest in the period between 1990 and 2003, and in the water and mixture area no big differences were noticed.

Table 1. Results from the land cover NDVI classification for full study area from the given years presented in percentage.

\begin{tabular}{|c|cccccc|}
\hline Year & $\mathbf{1 9 8 4}$ & $\mathbf{1 9 9 0}$ & $\mathbf{2 0 0 3}$ & $\mathbf{2 0 0 9}$ & $\mathbf{2 0 1 1}$ & $\mathbf{2 0 1 5}$ \\
\hline Type(\%) & 0.324 & 0.330 & 0.709 & 1.131 & 0.379 & 0.025 \\
Water & 24.682 & 31.910 & 46.435 & 39.170 & 40.839 & 46.022 \\
Mixture & 52.825 & 55.914 & 42.973 & 44.111 & 47.413 & 49.475 \\
Vegetation & 22.169 & 11.846 & 9.883 & 15.588 & 11.369 & 4.401 \\
\hline
\end{tabular}

Table 2. Results from the land cover NDVI classification for every municipality from the given years presented in percentage

\begin{tabular}{|c|c|c|c|c|c|c|c|c|c|c|}
\hline Type & Year & Dzepchishte & Poroj & Tetovo1 & Tetovo 2 & Tetovo3 & M_Rechica & G_Rechica & G_palchi & D_palchi \\
\hline \multirow{6}{*}{ 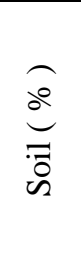 } & 1984 & 12.23 & 12.84 & 43.16 & 32.92 & 39.41 & 12.48 & 10.50 & 3.56 & 5.13 \\
\hline & 1990 & 16.83 & 19.94 & 54.78 & 39.93 & 54.95 & 19.40 & 14.80 & 4.63 & 4.57 \\
\hline & 2003 & 32.35 & 37.79 & 68.92 & 65.75 & 61.11 & 30.44 & 24.10 & 3.91 & 7.16 \\
\hline & 2009 & 26.37 & 33.02 & 54.89 & 51.76 & 56.07 & 26.82 & 25.30 & 9.96 & 10.86 \\
\hline & 2011 & 26.71 & 31.63 & 57.94 & 56.31 & 57.84 & 27.09 & 25.00 & 6.05 & 9.59 \\
\hline & 2015 & 34.04 & 38.55 & 59.01 & 61.41 & 63.79 & 33.03 & 33.68 & 11.01 & 15.25 \\
\hline \multirow{6}{*}{ 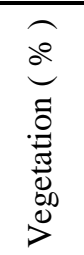 } & 1984 & 26.80 & 37.68 & 9.25 & 16.85 & 12.13 & 27.86 & 22.80 & 16.37 & 44.21 \\
\hline & 1990 & 8.50 & 23.28 & 3.15 & 7.89 & 1.77 & 15.47 & 12.70 & 4.98 & 33.86 \\
\hline & 2003 & 4.60 & 7.93 & 0.39 & 3.76 & 2.75 & 21.89 & 9.40 & 12.10 & 33.25 \\
\hline & 2009 & 18.13 & 16.67 & 4.39 & 10.00 & 11.41 & 27.09 & 25.00 & 6.05 & 9.59 \\
\hline & 2011 & 10.93 & 11.38 & 3.33 & 6.04 & 7.02 & 31.84 & 14.40 & 18.15 & 27.41 \\
\hline & 2015 & 1.20 & 2.24 & 0.94 & 1.75 & 1.34 & 19.30 & 4.13 & 0.72 & 4.61 \\
\hline
\end{tabular}



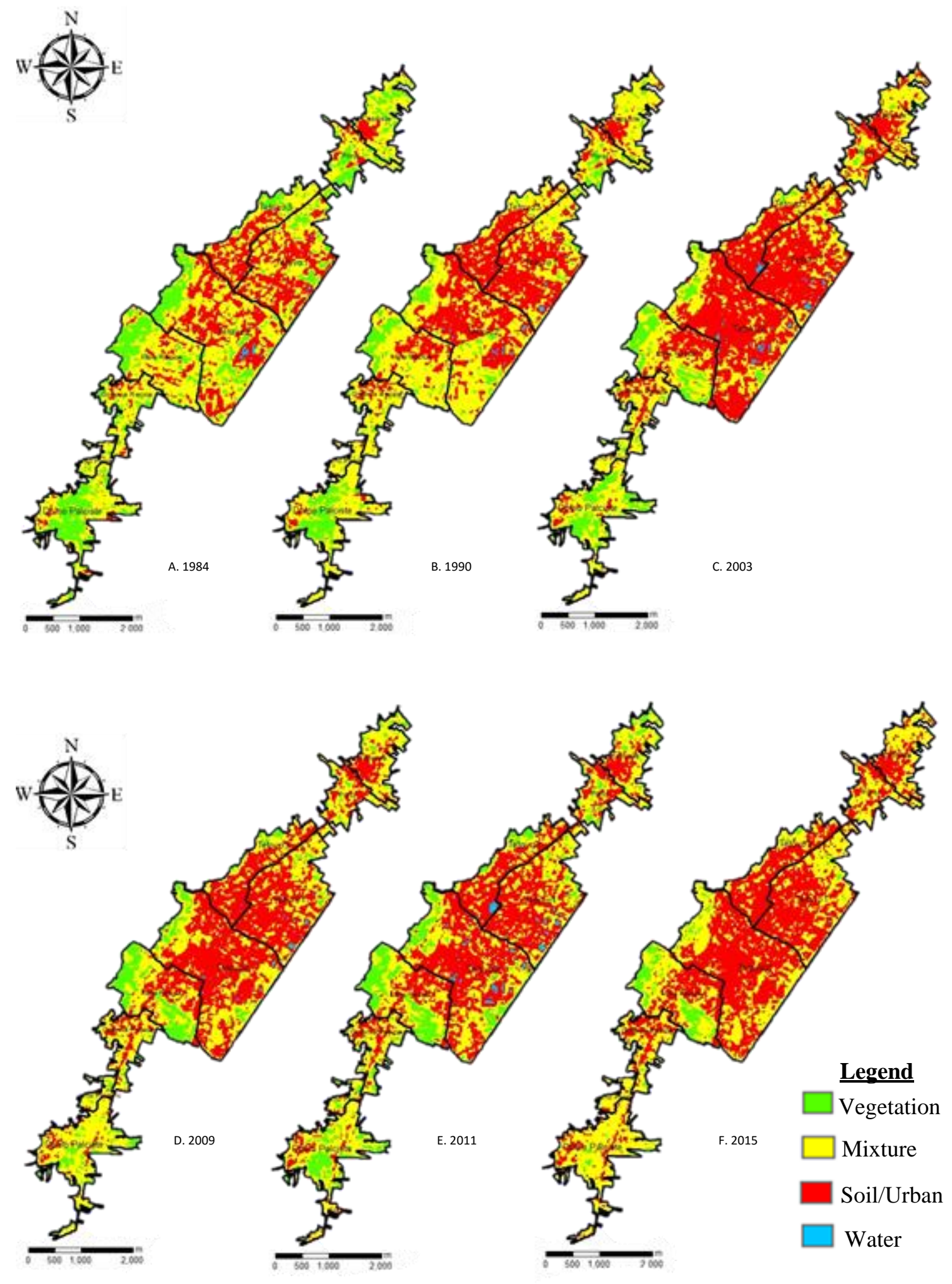

Figure 2. Land cover map from the NDVI classification of the full study area from a. 1984 , b. 1990 , c. 2003 , d. 2009 , e. 2011 , f. 2015. 
Continuous and regular monitoring of land use change is quite a valid method referenced in achieving sustainable development and environmental protection goals. As a result of the natural population increase in the city of Tetovo, a need for city expansion has appeared. With this need, a lot of agricultural fields has been converted to residential areas. The impact of the location and the shape of the transport network, the expansion has growth drastically in the western, eastern part and the southern part. Because of the mountain on the one side, the urban area is growing toward to the plain that had led to a rapid narrowing of the agriculture fields. The world's ecological, economic and social sense intertwined nowadays, the correct and appropriate use of the land is of great importance. Especially rapidly shrinking and rapidly growing agricultural land is a threat to the region, the country and even to the world's population. The new housing needs have come as a result of the rapid population growth that have been the reason for the rapid growth of the city. Agricultural areas that are located in the first row among the land uses are negatively affected by the city growth. Sustainable land use can only be accomplished with a preference for the natural and cultural potential and ecological structure determination of an appropriate land use.

\section{REFERENCES}

[1] Ustin, S., Manual of Remote Sensing: Remote sensing for natural resource management and environmental monitoring. 2004: Wiley Hoboken, NJ, USA.

[2] Sabins, F.F., Remote Sensing: Principles and Interpretation. 1997. 92: p. 754-754.

[3] Chander, G., B.L. Markham, and D.L. Helder, Summary of current radiometric calibration coefficients for Landsat MSS, TM, ETM+, and EO-1 ALI sensors. Remote Sensing of Environment, 2009. 113(5): p. 893-903.

[4] Salem, T.E., D. Ibitayo, and B.R. Geil, Validation of infrared camera thermal measurements on high-voltage power electronic components. Ieee Transactions on Instrumentation and Measurement, 2007. 56(5): p. 1973-1978.

[5] http://www.numbeo.com/, N.

[6] Orhan, O., S. Ekercin, and F. Dadaser-Celik, Use of Landsat Land Surface Temperature and Vegetation Indices for Monitoring Drought in the Salt Lake Basin Area, Turkey. Scientific World Journal, 2014.

[7] Sobrino, J.A. and N. Raissouni, Toward remote sensing methods for land cover dynamic monitoring: application to Morocco. International Journal of Remote Sensing, 2000. 21(2): p. 353-366. 